\title{
Protección de los derechos de los menores con ambigüedad sexual (Sentencias de un juez de tutela y de la Corte Constitucional colombiana - Sala quinta de revisión)
}

\author{
Comentario de Julia Sandra Bernal Crespo*
}

Ciudad XX, catorce de septiembre de dos mil uno

\section{VISTOS Y OIDOS:}

Primero: Los señores $\mathrm{XX}^{1}$, interpusieron acción de tutela en nombre de su menor hijo y en contra del Seguro Social -Seccional ZZ-, por estimar vulnerados los derechos fundamentales del menor a la integridad física, al libre desarrollo de la personalidad, a la igualdad, al debido proceso y, en general, a los derechos fundamentales de los niños, como consecuencia de la actuación de la entidad demandada, que se ha negado a practicarle una cirugía necesaria para la asignación de su sexo, dada la presencia de un cuadro médico de virilización por hiperplasia suprarrenal congénita (Pseudohermafroditismo femenino).

SEGUNDO: El menor NN nació en condiciones de aparente normalidad el día 15 de enero de 1994, siéndole asignado el sexo masculino dadas sus condiciones fenotípicas (presencia de falo). Sin embargo, los padres teniendo en cuenta las ecografías practicadas en la etapa prenatal aguardaban el nacimiento de una niña.

A mediados de julio de 1998, por intermedio de la Unidad genética-médica de la Facultad de Medicina de la Universidad de Antioquia, a petición del Seguro Social, se realizó un estudio de linfocitos de médula ósea para determinar el cariotipo del menor, resultando que el infante presenta una constitución genética 46-XX (mujer).

En enero 27 de 2000, se le diagnosticó definitivamente al menor la presencia de un cuadro médico de Pseudohermafroditismo femenino con virilización extrema y se le sugiere acudir ante un juez de tutela para que, previa su autorización, pudiese hacerse efectivo el tratamiento que se consideraba recomendable.

* Doctora en Derecho; Profesora de la Universidad del Norte de Barranquilla. Kilómetro 5 carretera Puerto Colombia. Barranquilla (Colombia).sbernal@uninorte.edu.co

${ }^{1}$ En esta sentencia se desconoce el nombre del juez de tutela, la ciudad, el nombre del menor y de sus padres por orden expresa de la Corte constitucional, todo lo anterior con el fin de proteger la intimidad personal y familiar de los peticionarios y del menor. 
De acuerdo con el médico jefe de cirugía infantil de la Clínica ZZ del Seguro Social, el problema del menor radica en que “... se trata de una mujer genética con una hiperplasia suprarrenal congénita con virilización extrema; ocasionado por un trastorno en el metabolismo y sintesis de las hormonas producidas por la suprarrenal, tiene la deficiencia de una encima que no permite que se sintetice adecuadamente los estrógenos, y se produzcan cantidades excesivas de andrógenos. Puntualizando tenemos a un ser quien social, grupal y personalmente tiene identificación hacia el género masculino en forma clara; pero quien genéticamente tiene la dotación de genes y órganos internos femeninos correspondientes a una mujer...".

Afirman los accionantes, que de acuerdo con dictamen médico, el menor padece de retardo mental y sicomotriz en un $60 \%$. Por esta razón, ni aún cumpliendo la mayoría de edad estaría apto para consentir en la operación de asignación de sexo.

Tercero: Los tutelantes pretenden que se ordene al Seguro Social practicar la cirugía necesaria para asignar el sexo del infante y suministrar la asistencia médica-hospitalaria (incluidos los medicamentos) que el menor llegue a necesitar.

Igualmente, solicitan la inaplicación de la doctrina sentada por esta Corporación, en relación con el requerimiento de contar con el consentimiento informado del menor para la práctica de la cirugía de asignación de sexo en tratándose de estados 'intersexuales', dadas las condiciones particulares del caso.

Cuntro: El Juez de Tutela realizó un acopio de pruebas destinado a definir el caso en concreto y, posteriormente, enfocó su análisis siguiendo la doctrina de la Corte sobre el tema.

Con base en dictamen pericial del Instituto de Medicina Legal del 30 de octubre de 2001, el juez llegó a la conclusión de que el niño no padece de retardo mental alguno, como consideraban sus padres, sino que su condición sicomotriz es atribuible a dificultades de aprendizaje, debido al déficit educacional y a los conflictos que su maduración sexual temprana le generan.

Siguiendo lo expuesto por la Corte Constitucional en anteriores sentencias el juez de instancia sostiene que la autorización para la práctica de una cirugía de asignación de sexo para un niño de 7 años debe ser dada por él mismo, ya que se trata de una intervención altamente invasiva que puede tener repercusiones graves en el desarrollo de su vida posterior. De esta manera, el despacho sostiene que: “...corresponde a la propia persona definir su identidad sexual, con la asesoría de un grupo interdisciplinario de médicos, cirujanos, urólogos, endocrinólogos pediatras, genetistas, ginecólogos, sicólogos, siquiatras y trabajadores sociales que hagan intervención tanto al menor como a su grupo familiar". Así, una vez el paciente tenga pleno conocimiento del procedimiento médico apropiado y de sus posibles implicaciones, podría estar en condiciones de prestar su consentimiento.

Quinto: De lo anteriormente expuesto: Este despacho después de analizar las pruebas aportadas y teniendo en cuenta los criterios de la $\mathrm{H}$. Corte Constitucional concluye que, como no existe un evidente riesgo de que se comprometa el derecho a la vida del menor si no se práctica la operación, no es posible que los padres autoricen la intervención y 
los tratamientos hormonales para su hijo, que ya tiene más de siete años, por lo que considera que esas intervenciones sólo podrán ser adelantadas con el consentimiento informado del [menor...], por ello la tutela no debe ser concedida, acogiendo la solicitud concreta de los padres que pretenden que el juez de tutela autorice los procedimientos. Sin embargo, es necesario que se tomen las medidas necesarias para proteger los derechos fundamentales del menor. Por ello este Despacho protegerá el derecho a la identidad sexual, al libre desarrollo de la personalidad y a la igualdad de los peticionarios y ordenará a la E.P.S. Seguro Social que tomen las medidas necesarias para que este niño y su grupo familiar reciban el apoyo psicoterapéutico e interdisciplinario que requieran, para que puedan comprender adecuadamente la situación que enfrentan, para lo cual deberá conformarse un equipo interdisciplinario, que debe incluir no sólo profesionales de la medicina sino también psicoterapeuta y un trabajador social, que deberán acompañar al menor $\mathrm{NN}$ y a su familia en todo este proceso. A este equipo corresponderá establecer cuando el menor goza de la autonomía suficiente para prestar su consentimiento para que se adelanten las cirugías y los tratamientos hormonales, obviamente si el paciente así lo elige.

Bogotá, D.C., veintisiete (27) de noviembre de dos mil dos (2002).

\section{VISTOS Y CONSIDERANDO:}

Primero: Que la Corte Constitucional es competente para revisar la sentencia proferida dentro del proceso de la referencia, con fundamento en lo dispuesto por los artículos 86 y 241 numeral $9^{\circ}$ de la Constitución Política, en concordancia con los artículos 31 a 36 del Decreto 2591 de 1991.

Segundo: Que se revisará la sentencia del Juez de Tutela, pues se impone establecer sí, dadas las circunstancias del caso, para proceder a la protección de los derechos fundamentales invocados para el infante, resulta viable que la intervención requerida para la asignación de sexo se realice a partir del consentimiento sustituto de los padres, o si, por el contrario, como se trata de un menor que ha sobrepasado el umbral de los cinco años, se hace indispensable, de conformidad con la línea jurisprudencial fijada por esta Corporación, esperar a que adquiera la madurez suficiente para adoptar por sí mismo dicha decisión.

Tercero: Que esta Corporación se ha ocupado en varias oportunidades del estudio de los problemas del consentimiento en torno a los tratamientos médicos del 'hermafroditismo' y de otros 'estados intersexuales' o de 'intersexos'.

Que ésta Corporación ha considerado que era necesario establecer unos límites de raigambre constitucional que permitiesen ponderar el principio de autonomía del paciente frente al principio de beneficencia, según el cual, el Estado y los padres deben proteger los intereses del infante. 
la Corte ha afirmado que la específica orientación sexual de un individuo constituye un asunto que se inscribe dentro del ámbito de autonomía individual que le permite adoptar, sin coacciones ajenas, los proyectos de vida que considere pertinentes, siempre y cuando, con ellos, no vulnere el orden jurídico y los derechos de los demás. Pero, en el caso de los estados 'intersexuales', la proyección de la autonomía y el establecimiento de la real identidad sexual, no corresponden al libre ejercicio de una opción peculiar y espontánea destinada a trazar una determinada vocación sexual de la persona ante la sociedad, como sucede en los casos de transexualismo o cambios de sexo. Por el contrario, las cirugías y los tratamientos hormonales de asignación de sexo, en dichos casos, lejos de aspirar a modificar los genitales externos del individuo, suponen la necesidad de contribuir a superar un estado de ambigüedad afirmando las características predominantes de un determinado género.

En otras palabras, no se trata del ejercicio de una opción personal y espontánea sobre una determinada vocación sexual, sino de un mandato imperativo que ante la condición clínica del paciente, exige la intervención de la ciencia médica para definir un sexo, más no para cambiarlo. Por ello, en este caso, el conflicto jurídico se plantea entre la necesidad de una temprana asignación de género, con el fin de garantizar el desarrollo de los atributos proyectivo, estimativo y temporal del ser, destinados a forjar su propio proyecto vital o de existencia, en contraste con el imperativo de una intervención sobre la sexualidad de la persona a partir de su consentimiento informado. En resumen, se trata de la ponderación de la autonomía del menor para disponer de su propio cuerpo, cuando las condiciones clínicas y el nivel de raciocinio le permiten optar por sí mismo en la afirmación de su sexo, frente a la posibilidad de proyectar un consentimiento sustituto a futuro, en aras de salvaguardar el ejercicio de las condiciones vitales que le permiten a cada 'ser' la construcción constante y permanente de su personalidad.

En este orden de ideas, es posible inferir que la doctrina constitucional expuesta por esta Corporación en asuntos de "hermafroditismo" o "estados intersexuales", supone la necesidad de evaluar y ponderar, frente a cada caso en concreto, las distintas variables que determinan la procedencia del consentimiento informado del menor con los elementos que dan preponderancia al consentimiento sustituto de sus padres orientado hacia futuro. A saber: (i) la urgencia del tratamiento; (ii) El impacto y/o riesgo del mismo sobre la autonomía actual y futura del niño; y (iii) la edad y/o madurez del menor.

CuARto: Que en relación con la edad se ha considerado que a partir de los 5 años el niño ha superado el umbral crítico de identificación del género y a juicio de la Corte, ante los riesgos excesivos que este tipo de operaciones plantean, no aparecía de manera clara la utilidad de practicarlas antes de que sea el propio paciente quien las autorice. De esta manera, la decisión sobre la realización de la operación de asignación de sexo para mayores de 5 años corresponde al propio menor, ajustando su ocurrencia a la necesidad de evitar las consecuencias traumáticas de la pubertad.

Por otra parte, cuando se supera el citado umbral, no puede imponerse exclusivamente el consentimiento informado del menor como norma general; esto, en atención a la multiplicidad de factores que convierten cada asunto médico en un universo único 
e irrepetible. De ahí que, en ciertos casos, quepa acudir a la opción de lo que se ha denominado consentimiento asistido que comporta el consentimiento prestado por los padres coadyuvado por la expresa voluntad del menor, y de acuerdo con los profesionales de la salud, obviamente, destinando su lex artis a la defensa y protección de la autonomía e integridad del infante.

En conclusión, antes de los cinco años se debe proceder con base en la regla general del consentimiento sustituto, después, sólo con fundamento en el consentimiento informado del menor, a menos que, en atención a las particularidad de cada caso se disponga una opción distinta, como es el consentimiento asistido, siguiendo para el efecto los derroteros de opciones, factores o variables a los que hace referencia la jurisprudencia constitucional.

Quinto: En este caso en concreto, los médicos permitieron catalogar la situación clínico-patológica del menor como: "virilización por hiperplasia suprarrenal congénita" conocida en la doctrina médica especializada como una modalidad de Pseudohermafroditismo femenino. A partir de dicho análisis y teniendo en cuenta el desarrollo del menor, tanto los médicos tratantes como el equipo interdisciplinario de Pediatría y Cirugía Infantil del Seguro Social consideraron que: "por la edad, los patrones fenotípicos y sociales NN debe seguir siendo tratado como bombre". Sin embargo, es preciso reconocer que valorando exclusivamente sus características cromosómicas y gonadales podría igualmente asignársele el sexo femenino.

En el presente caso, tanto los médicos, los padres y aún el mismo menor parecen tener la convicción que la solución adecuada a la indeterminación sexual que padece $\mathrm{NN}$, es la asignación del género masculino. Sin embargo, en la declaración ante el juez de instancia, el infante manifiesta un principio de duda al sostener que: "yo pienso que cuando sea grande me pienso casar y tener hijos porque me encantan los bebes, yo quiero seguir siendo así como soy como un hombre, si no pudiera tener hijos pensaría si ser hombre o mujer".

Por otra parte, en el análisis psicológico del Instituto de Medicina Legal, se estima que aunque el menor está en condiciones de dar su aquiescencia en la adopción de una determinada vocación sexual y que, concibe a la supuesta niña de su interior como un producto de su imaginación, contestó a la pregunta: "¿Tú como quisieras ser? Como soy por fuera como un niño, no importa que yo cometa errores o no, no quiere ser como soy yo por dentro como una niña porque de la otra mitad no entiendo nada de ella, yo escogí la de hombre porque que pereza que yo fuera como niña con cara de hombre como todo fuera como de hombre porque si yo fuera como una niña con cara de hombre se notara que era hombre, yo nunca me he imaginado como una niña (...)".

Por lo cual, podemos concluir que: (i) cromosómica y gonadalmente NN es mujer, mientras fenotípicamente su apariencia externa se identifica a la de un varón; (ii) éste en relación con su género tiene una marcada identidad hacia el sexo masculino; (iii) Por otra parte, independientemente de la decisión que se adopte es indispensable operar al menor para cercenar, moldear o extirpar órganos genitales internos o externos y; (iv) siempre será imprescindible complementar dicho tratamiento operatorio con el suministro hormonal requerido. 
Las declaraciones médicas sostienen que la ausencia de la cirugía de asignación de sexo no compromete ni amenaza la salud física ni la vida del menor, siendo, por el contrario, su principal motivación la tranquilidad psicosexual y social de éste y su familia.

A partir del dictamen médico del instituto de medicina legal que concluye que desde el punto de vista psicológico, NN, no presenta retardo mental; es posible sostener que el menor de 8 años, NN es una persona capaz dentro de los límites propios de su edad y que requiere de un adecuado seguimiento psicológico, psiquiátrico y de asistencia social para poder obtener su aquiescencia en la adopción de un determinado sexo.

Sexto: Ahora bien, para la Corte surge como interrogante, si dadas las especiales condiciones clínico-patológicas del menor, es procedente la reiteración plena de la doctrina constitucional expuesta en esta materia o si es apropiado darle prelación a la tesis del consentimiento asistido. En el presente caso, como se expuso con anterioridad existe un pleno consenso en asignar el sexo masculino al menor. Sin embargo, en una de las piezas transcritas parecería que existen dudas en él, sobre cuál debe ser la adecuación de su sexo en función de la posibilidad procrear. Precisamente, en estos eventos, adquiere un papel preponderante la asistencia de los médicos tratantes y de los padres, en orden a permitir, que en consonancia con su nivel de madurez sicológica el menor pueda expresar su voluntad.

De las consideraciones expuestas, la Corte puede concluir que, en el presente caso, es procedente el denominado consentimiento asistido, con el fin de salvaguardar los derechos fundamentales a la identidad personal y sexual, al libre desarrollo de la personalidad y a la salud integral del menor. Esta modalidad comporta el consentimiento prestado por los padres, con la asistencia y salvaguarda de un equipo interdisciplinario de profesionales de la salud, siempre y cuando no exista oposición del infante mediante su expresa voluntad, en atención al deber de asistencia e información que tienen los médicos en torno al nivel de madurez del menor NN.

En mérito de lo expuesto, la Corte Constitucional de la República de Colombia, en nombre del pueblo y por mandato de la Constitución

\section{RESUELVE}

PRIMERo.- TUTELAR el derecho a la intimidad de los peticionarios y del menor NN, para cuyo efecto, sus nombres no podrán ser divulgados, y el presente expediente queda bajo estricta reserva, y sólo podrá ser consultado por los directamente interesados, conforme a lo señalado en el fundamento jurídico $\mathrm{N}^{\circ} 2.4$ de esta Sentencia. El Secretario General de la Corte Constitucional y el Secretario del Juzgado XX que decidió en primera instancia el caso, deberán garantizar esta estricta reserva.

SEGUNDO.- CONFIRMAR la Sentencia del Juzgado XX, de 14 de septiembre de 2001, en relación con la protección a los derechos a la identidad personal y sexual, al libre desarrollo de la personalidad y a la salud, pero con el alcance previsto en esta providencia. 
TERCERO.- ORDENAR al Seguro Social que:

a) Dentro de las 48 horas siguientes a la notificación de esta Sentencia, INTEGRE un equipo interdisciplinario conformado por médicos (cirujanos, urólogos, endocrinólogos, pediatras y psiquiatras), psicólogos y trabajadores sociales, con el fin de que asistan, orienten y asesoren al menor NN y a sus padres en el proceso de toma de decisión de la práctica de la cirugía de asignación de sexo y el suministro de los tratamientos hormonales indispensables. Para tales efectos, el equipo interdisciplinario deberá realizar los exámenes, diagnósticos y evaluaciones necesarias.

b) Una vez se haya prestado la asesoría a que se ha hecho referencia, y el menor NN y sus padres estén suficientemente informados de las consecuencias de llevar a cabo la cirugía y los tratamientos de asignación de sexo, consulte formalmente al menor NN y a sus padres acerca de la decisión final adoptada, por intermedio del equipo interdisciplinario.

c) En caso de que ésta sea afirmativa y coincida con el concepto emitido por el equipo interdisciplinario, REALICE la cirugía en el término de los 15 días siguientes a dicha manifestación de voluntad. Así mismo, deberá realizar los tratamientos hormonales requeridos y cualquier otro tratamiento post-operatorio que sea indispensable, según concepto del grupo interdisciplinario y de conformidad con la evolución del paciente.

CuArto.- En caso de que la decisión del menor no coincida con la de sus padres o que la decisión del menor y sus padres no coincida con el concepto del equipo interdisciplinario, no podrá realizarse la cirugía de asignación de sexo. Ello no obsta para que la misma se realice posteriormente, cuando así lo soliciten, por haber coincidido en su voluntad, el menor NN y sus padres, y dicha voluntad coincida con el concepto emitido por el equipo interdisciplinario. Para tales efectos, se ORDENA al Juez XX que vigile y tome las medidas necesarias para el cumplimiento de este numeral.

QUINTO.- LÍBRENSE las comunicaciones de que trata el artículo 36 del Decreto 2591 de 1991, para los efectos allí contemplados.

Cópiese, notifíquese, insértese en la gaceta de la Corte Constitucional y Cúmplase.

Referencia: expediente T-541.423.

Sentencia T-1025 de 2002

Magistrado Ponente: Rodrigo Escobar Gil

\section{COMENTARIO}

Pienso que en la actualidad nos encontramos incursos en un cambio de paradigma sobre la ambigüedad sexual. Son muchos los cuestionamientos que se están generando tanto 
dentro de los profesionales e investigadores vinculados con el manejo de los estados intersexuales, como de los propios individuos que nacen con los genitales ambiguos, y que hacen relación a que la intersexualidad sea definida como una patología que requiere de una solución. Postulo que se puede considerar a los estados intersexuales como variantes de la diferenciación sexual, estados intermedios de un dimorfismo sexual de nuestra especie biológica, sin establecer valoraciones relevantes, ni jurídica ni éticamente. Para ello es necesario que el cambio de paradigma científico deba ir acompañado de un cambio cultural que considere la diversidad y reconozca la autonomía del individuo y la libre fijación de su identidad que incluye su sexualidad.

Las Organizaciones Mundial de la Salud (OMS) y Panamericana de la Salud (OPS) ya están contribuyendo a este cambio de paradigma. En acta sobre la reunión de consulta realizada en Guatemala en el mes de mayo del año $2000^{2}$ establece que la "identidad de género" define el grado en que cada persona se identifica como masculina o femenina o alguna combinación de ambos, y que determina la forma en que las personas experimentan su género y contribuye al sentido de identidad, singularidad y pertenencia. En el acta además se determina que la "identidad sexual" incluye la manera como la persona se identifica como hombre o mujer, o como una combinación de ambos (Lo subrayado es mío)...

Creo que en Colombia la Doctrina Constitucional está abierta al cambio de paradigma, pues en las sentencias sobre el tema privilegia un marco de trabajo de colaboración e intercambio interdisciplinario entre expertos, pacientes y familiares, lo que es fundamental para llegar a un lenguaje común que no genere confusión, y que privilegie la perspectiva del paciente, su autonomía y responsabilidad en las decisiones de los tratamientos que se van a implementar o que no se van a realizar.

Sin embargo lo anterior, considero que la Corte no es consecuente con sus argumentos explicativos, cuando fija, basado en el criterio de edad ( 5 años), que si el menor tiene menos de 5 años se requiere para realizar las intervenciones quirúrgicas y los tratamientos hormonales el consentimiento sustituto de los padres. El consentimiento sustituto de los padres bajo la modalidad de "consentimiento orientado hacia el futuro" significa que la decisión tomada por los padres beneficia al menor, le protege sus derechos fundamentales, y que en el futuro el menor reconocerá que la intervención fue correcta. Sin embargo, sabemos que en lo que respecta a la importancia y urgencia del tratamiento para la salud del menor existen cuestionamientos científicos a la necesidad de los procedimientos de adecuación genital como única alternativa posible; que además, en cuanto al grado de afectación de la autonomía estas operaciones y tratamientos son irreversibles y por ello los cuestionamientos de sujetos operados sin su conocimiento y/o sin su consentimiento, en los que aparece patente que el consentimiento sustituto de los padres no cumplió con los objetivos de un consentimiento proyectado hacia futuro.

${ }^{2}$ OPS, OMS. Promoción de la salud sexual. Recomendaciones para la acción. Acta de una reunión de consulta convocada por las OPS, OMS en colaboración con la Asociación Mundial de Sexología, celebrada en Guatemala del 19 al 22 de mayo de 2000. 
Si la readecuación de los genitales y/o los tratamientos hormonales no son vitales, ¿por qué no se estudian otras alternativas o se espera simplemente a que el menor tenga capacidad suficiente, en el sentido de que tenga la autonomía para decidir o no sobre un tratamiento u operación, sin importar la edad? Si cuando toma la decisión sigue siendo menor de edad, hablaríamos de la modalidad de consentimiento asistido. De esta forma se cumpliría con los deberes que tienen el Estado y los padres de "protección" de la integridad de las condiciones psicobiológicas necesarias para que el menor pueda ejercer su autonomía presente o futura, decisión que sólo a él le corresponde pues estamos hablando de algo inherente a la persona misma, la fijación de su identidad sexual. Cuando carece de esta autonomía, la protección de los derechos de los menores con ambigüedad sexual debe basarse, a nuestro modo de ver, en el principio de no maleficencia, en no causarle daño o en causar el menor daño posible, en otras palabras en protegerlo de un perjuicio ${ }^{3}$.

En conclusión, proponemos se dé aplicación con base en el bloque de constitucionalidad $^{4}$ a la prevalencia de los derechos fundamentales de los niños, uno de los cuales es el de su identidad sexual y de género, que debe poder incluir la opción de no ser clasificado ni como femenino ni como masculino. El desconocimiento de la posibilidad de esta alternativa conlleva a la vulneración al derecho a su libertad, a su salud psicobiológica y lo más importante a su dignidad como ser humano, al tratamiento digno por su condición de ser humano sin distinción de edad, sexo, condición, estirpe o clasificación sexual, en otras palabras, al respeto como persona.

3 “Según el modelo clásico, las decisiones de sustitución se hacían siempre proyectando sobre el incapaz lo que la familia, el médico, el juez o toda la sociedad consideraban que era su 'beneficio' o su 'mayor interés'. En la situación moderna eso ya no es posible, dado que la sociedad no puede ni debe determinar el beneficio de una persona, capaz o incapaz, sino sólo protegerla del perjuicio. Pero eso no significa que no pueda y deba intentarse definir lo que es el mayor beneficio de un niño” (Gracia, Martín, \& Ríos, 2001: 181).

4 "Pactos dentro de los que se puede mencionar: El Pacto de San José de Costa Rica, la Declaración de Ginebra de 1924 sobre los derechos del niño, la Declaración de los Derechos del Niño adoptada por la asamblea general el 20 de noviembre de 1959, y reconocida en la Declaración Universal de Derechos Humanos, en el Pacto Internacional de Derechos Civiles y Políticos (artículos 23 y 24), en el Pacto Internacional de Derechos Económicos, Sociales y Culturales (artículo 10), en la Convención de Viena y en los estatutos e instrumentos pertinentes de los organismos especializados y de las organizaciones internacionales que se interesan en el bienestar del niño, y que han consagrado la protección especial a la niñez. De esta manera lo expresa la Corte Constitucional en diversas intervenciones al aludir directamente al desarrollo de los derechos fundamentales de la identidad, la dignidad y el libre desarrollo de la personalidad" (Velásquez, González, \& Sarmiento, 2007: 222). 